\title{
Reactivity of chlorine radical with submicron palmitic acid particles: kinetic measurements and product identification
}

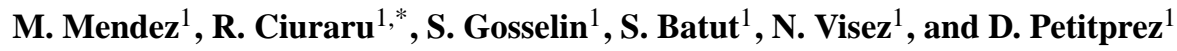 \\ ${ }^{1}$ Laboratoire Physicochimie des Processus de Combustion et de l'Atmosphère (PC2A) CNRS UMR8522 Université Lille 1, \\ 59655 Villeneuve d'Ascq, France \\ * now at: IRCELYON, Institut de Recherches sur la Catalyse et l'Environnement de Lyon, CNRS UMR5256, Université \\ Lyon 1, 69626 Villeurbanne Cedex, France
}

Correspondence to: D. Petitprez (denis.petitprez@univ-lille1.fr)

Received: 24 April 2013 - Published in Atmos. Chem. Phys. Discuss.: 25 June 2013

Revised: 4 October 2013 - Accepted: 28 October 2013 - Published: 3 December 2013

\begin{abstract}
The heterogeneous reaction of $\mathrm{Cl}^{\bullet}$ radicals with submicron palmitic acid (PA) particles was studied in an aerosol flow tube in the presence or in the absence of $\mathrm{O}_{2}$. Fine particles were generated by homogeneous condensation of PA vapours and introduced into the reactor, where chlorine atoms were produced by photolysis of $\mathrm{Cl}_{2}$ using UV lamps surrounding the reactor. The effective reactive uptake coefficient $(\gamma)$ has been determined from the rate loss of PA measured by gas chromatography-mass spectrometer (GC/MS) analysis of reacted particles as a function of the chlorine exposure. In the absence of $\mathrm{O}_{2}, \gamma=14 \pm 5$ indicates efficient secondary chemistry involving $\mathrm{Cl}_{2}$. GC/MS analysis has shown the formation of monochlorinated and polychlorinated compounds in the oxidized particles. Although the PA particles are solid, the complete mass can be consumed. In the presence of oxygen, the reaction is still dominated by secondary chemistry but the propagation chain length is smaller than in the absence of $\mathrm{O}_{2}$, which leads to an uptake coefficient $\gamma=3 \pm 1$. In the particulate phase, oxocarboxylic acids and dicarboxylic acids were identified by GC/MS. The formation of alcohols and monocarboxylic acids is also suspected. A reaction pathway for the main products and more functionalized species is proposed. All these results show that solid organic particles could be efficiently oxidized by gas-phase radicals not only on their surface but also in bulk by mechanisms which are still unclear. They help to understand the aging of primary tropospheric aerosol containing fatty acids.
\end{abstract}

\section{Introduction}

The concentration of organic matter in marine environments exhibits a seasonal behaviour, which dominates the chemical composition of fine particulate matter during periods of high biological activity (Yoon et al., 2007; O'Dowd et al., 2004; Cavalli et al., 2004; Sciare et al., 2008). Cells of living organisms in the oceans decompose after their death and the hydrophobic cellular constituents accumulate on the water surface, forming a sea-surface micro-layer of 1 to $1000 \mu \mathrm{m}$ thickness (Hardy, 1982). When sea-salt aerosols (SSA) are generated by the mechanical ejection of droplets from waves and winds, these organic compounds are also ejected, thus becoming a component of the newly formed particles (Barger and Garrett, 1976; Gogou et al., 1998; Marty et al., 1979). Recent laboratory and field measurements have shown that the organic mass fraction of SSA increases from 0.1 to near 1 when the ambient aerosol aerodynamic diameter decreases from 1 to $0.1 \mu \mathrm{m}$ (Keene et al., 2007; Facchini et al., 2008). The exact mechanism for such large organic mass fraction of submicron SSA is not well understood.

Chemical analyses of organic compounds sampled in SSA have allowed for identification of fatty acid (C12-C18) compounds (Marty et al., 1979), contributing to up to $10 \%$ in mass of the total organic content of the particles (Mochida et al., 2002).

Molecular characterizations of SSA collected in marine air masses have shown that fatty acids (FA) consist of relatively short carbon chains (Tervahattu et al., 2002a, b; Mochida et al., 2002; Oros and Simoneit, 2001). Due to the hydrophobic 
properties of surfactants, the fatty acids are thought to form an organic coating around the inorganic core of the particles (Ellison et al., 1999; Rudich, 2003). When considering a monolayer coating, the surface coverage by FA is estimated to be of the order of 0.3 to $14 \%$ (Tervahattu et al., 2005; Mochida et al., 2002).

Fatty acids are also ubiquitous in airborne particles sampled in urban atmospheres (Oliveira et al., 2007). They were found to contribute to up to $50 \%$ of identified organic compounds from emission sources such as biomass burning (Nolte et al., 2001; Schauer et al., 2001; Fine et al., 2001), cooking (Schauer et al., 2002; He et al., 2004), and automobiles (He et al., 2006). Among the fatty acids, palmitic acid $\left(\mathrm{C}_{16} \mathrm{H}_{32} \mathrm{O}_{2}\right)$ is the most abundant one (Mochida et al., 2002).

Recent literature reviews have presented the physical and chemical processes which occur at the interface of airborne organic particles (Donaldson and Vaida, 2006; Rudich, 2003; George and Abbatt, 2010). Many heterogeneous reactions of atmospheric particles involve the main oxidant of the atmosphere (i.e. the hydroxyl radical $\mathrm{OH}^{*}$ ), which chemically alters their surfaces thus aging them. The intensity of this aging depends on various parameters such as meteorological conditions, size of the particle, and the chemical composition of the particle surface and bulk. Consequently, variability of these parameters leads to the observed spatial and temporal variability of the physical and chemical properties of atmospheric aerosols. These heterogeneous processes affect the optical, hygroscopic, and reactive properties of airborne particles, thereby making the prediction of their global and regional atmospheric impact uncertain. Although the $\mathrm{OH}^{*}$ radical is the primary daytime oxidant, halogen atoms $(\mathrm{Cl}$, $\mathrm{Br}$, and I) may also significantly participate in oxidation processes, especially in the marine boundary layer (MBL). Halogen species are emitted from anthropogenic sources, but important sources are also represented by the halogen release from SSA and associated heterogeneous reactions. $\mathrm{Cl}^{\circ}$ atoms are mainly generated from the photolysis of active chlorine species and their concentrations can be up to $10^{6}$ atom $\mathrm{cm}^{-3}$ (Spicer et al., 1998; Pechtl and von Glasow, 2007).

Recent atmospheric measurements (Osthoff et al., 2008) have shown that nitryl chloride $\left(\mathrm{ClNO}_{2}\right)$ is produced by heterogeneous reactions on sea-salt particles and accumulates during the night. At dawn, the photolysis of nitryl chloride produces a peak of $\mathrm{Cl}^{*}$ with an estimated rate of formation of $1 \times 10^{6}$ atom cm $^{-3} \mathrm{~s}^{-1}$.

This $\mathrm{Cl}^{\bullet}$ atom source seems modest relative to other oxidants. However, it has been reported that $\mathrm{Cl}^{\bullet}$ reacts faster than $\mathrm{OH}^{*}$ radicals with hydrocarbon compounds (Spicer et al., 1998) and may represent the major oxidant of the troposphere in coastal and industrialized areas, especially at dawn, when concentrations of $\mathrm{OH}^{*}$ radicals are low. While sources of reactive halogen species and halogen chemistry in the troposphere are relatively well studied, detailed chemical processes are still unknown (George and Abbatt, 2010).
Given the high reactivity of $\mathrm{Cl}^{\bullet}$ atoms with organic compounds and the ubiquity of $\mathrm{Cl}^{\circ}$ and fatty acids in the troposphere, especially in the MBL, it is obvious that this heterogeneous reactivity must be considered. However, only a few experimental studies between gas-phase radicals $\left(\mathrm{Cl}^{\circ}\right.$ or $\mathrm{OH}^{*}$ ) with condensed-phase organic compounds, including model organic surfaces, are reported.

Uptake coefficients of $\mathrm{OH}^{\bullet}$ on pure palmitic acid (PA) particles between 0.8 and 1 have been reported by McNeill et al. (2008). The authors also measured uptake coefficients for thin PA film coatings on solid and liquid $\mathrm{NaCl}$ particles, obtaining lower values than for pure PA experiments (solid, $\gamma^{\mathrm{OH}} \approx 0.3$; liquid, $\gamma^{\mathrm{OH}} \approx 0.05$ ). Experiments with chlorine atoms, generated from $\mathrm{Cl}_{2}$ photolysis, have also been considered as a model for radical-initiated oxidation chemistry which avoids the presence of reactive precursors or side products during generation of $\mathrm{OH}^{*}$. The reactive uptake of $\mathrm{Cl}^{\circ}$ atoms on self-assembled organic monolayers was studied by Moise and Rudich (2001) using a flow reactor coupled to a chemical ionization mass spectrometer. The uptake coefficient, measured by recording the rate of loss of $\mathrm{Cl}^{\bullet}$ radicals, was estimated to be in the range $(0.1<\gamma<1)$, close to the diffusion-limited loss rate.

Reactions of $\mathrm{Cl}^{\cdot}$ radicals in the presence of $\mathrm{O}_{2}$ have been studied using an aerosol flow tube to stand as a model of the radical-initiated oxidation of liquid-phase organic aerosols. In the case of reactions of $\mathrm{Cl}^{\bullet}$ radicals with dioctyl sebacate (DOS) particles (Hearn et al., 2007), in the presence of $\mathrm{O}_{2}$, the uptake coefficient has been determined by monitoring the rate of loss of DOS species. The uptake coefficient exhibits a value greater than unity $\left(\gamma_{\mathrm{DOS}-\mathrm{OH}}=1.7 \pm 0.3\right)$, indicating a radical chain chemistry. Products were mainly identified in the particles, showing an inefficient volatilization process.

More recently, heterogeneous reactions between $\mathrm{Cl}^{\circ}$ atoms and submicron squalane particles have been investigated in a photochemical aerosol flow tube (Liu et al., 2011). Secondary chain chemistry occurring in the liquid phase has also been demonstrated during this study. The measured uptake coefficient decreases from a value of $\sim 3$ for experiments performed without $\mathrm{O}_{2}$ to a value of 0.65 for experiments in the presence of $\mathrm{O}_{2}$. Product formation in condensed phase is controlled by competitive reaction rates of $\mathrm{O}_{2}$ and $\mathrm{Cl}_{2}$ with alkyl radicals.

All of these studies of heterogeneous reaction between radical species and organic surfaces or particles as a model for the oxidation of organic aerosols clearly emphasize the role of $\mathrm{OH}^{*}$ or $\mathrm{Cl}^{*}$ in initiating oxidation processes via an $\mathrm{H}$-abstraction pathway. This is followed by a chain reaction which can accelerate the overall rate of particle transformation. Concerning experiments with $\mathrm{Cl}^{\bullet}$ radicals, it was shown that more than $60 \%$ of the initial condensed matter can be consumed by the reactions. Several hypotheses have been put forth to explain these surprising observations: (1) a quite rapid surface renewal process and (2) an efficient secondary chain chemistry in the bulk. These processes might readily 
occur in the case of liquid droplets (DOS or squalane), but are limited by the diffusion of the species in the liquid phase for both reactants and products. In the case of solid particles, surface renewal can be induced by volatilization. Trapping of species within the particle or phase change of the surface layer cannot be excluded.

Chemical mechanisms adapted from the homogeneous phase have been proposed to interpret the formation of products mainly in the particulate phase, but reaction pathways still remain unclear due to the specificity of the condensed phase (for example, microscopic arrangement of the molecules, diffusion process in liquid/solid phase).

We present here the experimental results of heterogeneous reactivity between $\mathrm{Cl}^{\circ}$ and PA within an aerosol flow tube (AFT), where fine particles generated by homogeneous condensation of PA vapours are introduced with $\mathrm{Cl}_{2}$ as a radical precursor. $\mathrm{Cl}^{*}$ atoms are generated by photolysis of the molecular chlorine using UV lamps surrounding the reactor. Experiments have been conducted with and without $\mathrm{O}_{2}$. For both cases, uptake coefficients have been determined by monitoring the decay of PA by gas chromatography-mass spectrometer (GC/MS) analyses of collected particles on filters at the exit of the reactor. Identification of the reaction products in the condensed phase have been performed by GC/MS analyses and has led to the proposal of a detailed chemical mechanism for oxidation of carboxylic acids in particulate matter.

\section{Experimental section}

\subsection{Aerosol flow tube}

An atmospheric pressure aerosol flow tube (AFT) is used to investigate the heterogeneous reactivity of PA particles with chlorine atoms (Fig. 1). The AFT is a $1 \mathrm{~m}$ long and $10 \mathrm{~cm}$ inner diameter quartz tube surrounded by eight UV lamps (UVP, $365 \mathrm{BLB}, \lambda_{\text {mean }}=365 \mathrm{~nm}$ ). The particles and the gas-phase oxidant precursor are introduced into the upper flange of the reactor through two $1 / 4^{\prime \prime}$ stainless steel connectors. The total flow, monitored by mass flow meters, is fixed at $4.0 \mathrm{~L} \mathrm{~min}^{-1}$, which corresponds to a mean residence path time of $180 \mathrm{~s}$ in the AFT.

\subsection{Reactant generation}

Palmitic acid $(\geq 98 \%)$ was purchased from Roth; dichloromethane $(99.8 \%)$ from Sigma-Aldrich; both tetradecane $(\geq 98 \%)$ and hexadecane $(\geq 98 \%)$ from Fluka; $\mathrm{N}, \mathrm{O}-\mathrm{Bis}$ (trimethylsilyl) trifluoroacetamide, $\mathrm{C}_{8} \mathrm{H}_{18} \mathrm{~F}_{3} \mathrm{NOSi}_{2}$ - trimethylchlorosilane (BSTFA-TMCS) (99-1\%) solution from Supelco; the gases synthetic air 3.0 and nitrogen 4.6 from Praxair; and chlorine ( $1 \%$ of $\mathrm{Cl}_{2}$ in helium) from Air Liquide $(99.6 \%)$.

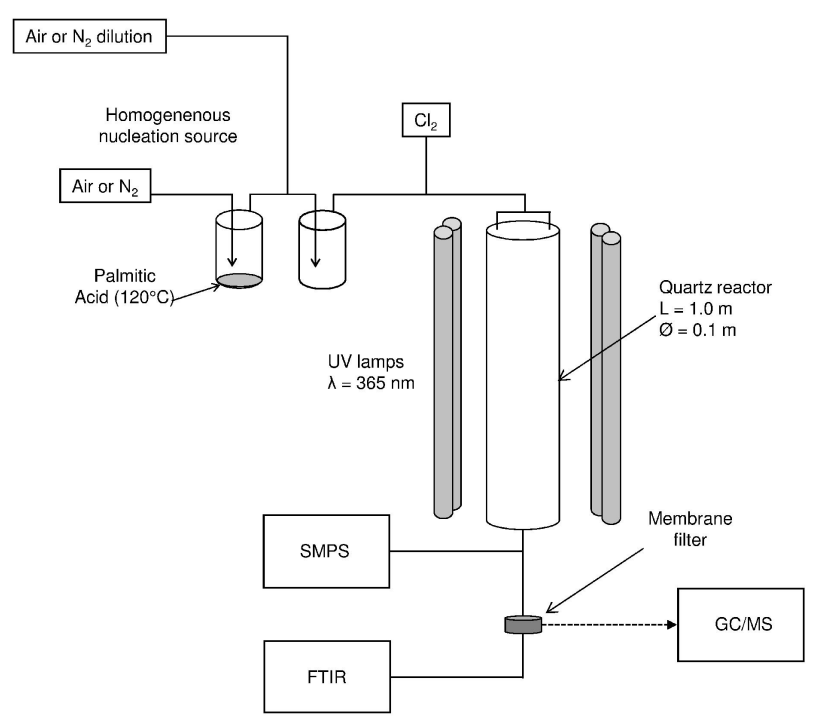

Fig. 1. Experimental setup, SMPS (scanning mobility particle sizer), FTIR (Fourier transform infrared spectrometer), and GC/MS (gas chromatography-mass spectrometer).

\subsection{Particle generation}

Palmitic acid particles are generated by homogeneous nucleation in a stream of $1 \mathrm{~L} \mathrm{~min}^{-1} \mathrm{~N}_{2}$ or $\mathrm{N}_{2} / \mathrm{O}_{2}$ flowing through a glass vessel containing $5 \mathrm{~g}$ of PA. A heating wire is wrapped around the glass vessel, and the PA temperature is kept constant $\left( \pm 1^{\circ} \mathrm{C}\right)$ using a temperature controller. The flow is diluted with $1 \mathrm{~L} \mathrm{~min}^{-1}$ of $\mathrm{N}_{2}$ or $\mathrm{N}_{2} / \mathrm{O}_{2}$ and sent to a condensation tube of $1.5 \mathrm{~L}$ volume at room temperature. The size distribution of the particles is continuously recorded by a scanning mobility particle sizer (SMPS) (model TSI 3080L) every 2 min. Palmitic acid particle density was assumed to be the solid-phase density $\left(d=0.852 \mathrm{~g} \mathrm{~cm}^{-3}\right.$; Lide, 2004). Depending on the heating temperature and flows, mass concentrations between 500 and $1000 \mu \mathrm{g} \mathrm{m}^{-3}$ of PA particles are generated. For a temperature of around $120^{\circ} \mathrm{C}$, the setup produces a log-normal particle size distribution with a mean surface-weighted diameter of $\sim 500 \mathrm{~nm}$ and a geometric standard deviation of $\sim 1.5$. Measuring the aerosol concentration before and after the AFT has revealed that the mean diameter is not modified and that at maximum a mass loss of $10 \%$ occurred while passing through the AFT.

\subsection{Atomic chlorine production}

The chlorine radicals are generated along the length of the AFT by powering all or some of the eight UV lamps. The $\mathrm{Cl}$ concentration can also be adjusted by controlling the $\mathrm{Cl}_{2}$ initial concentration in the AFT.

The chlorine radical concentration is measured by performing reference kinetic experiments with acetone. Molecular chlorine ( 3 to $20 \mathrm{ppm}$ ) and acetone (50 ppm) are 
introduced in the reactor and the reaction between acetone and $\mathrm{Cl}$ takes place with a second-order rate constant $\left(k_{\text {ref }}\right)$ of $2.09 \times 10^{-12} \mathrm{~cm}^{3}$ molecule ${ }^{-1} \mathrm{~s}^{-1}$ (Liu et al., 2011; George et al., 2007). The loss of acetone is monitored by Fourier transform infrared (FTIR) spectroscopy by integration of the absorbance of the $\mathrm{C}-\mathrm{C}$ stretching band at $1217 \mathrm{~cm}^{-1}$ (Perelygin and Klimchuk, 1974) between 1160 and $1260 \mathrm{~cm}^{-1}$. The loss rate of acetone can be expressed as

$v=\frac{\mathrm{d}[\text { Acet }]}{\mathrm{d} t}=-k_{\mathrm{ref}}[$ Acet $][\mathrm{Cl}]$.

Integration of Eq. (1) leads to determination of the chlorine exposure $\left(\langle\mathrm{Cl}\rangle_{t} \cdot t\right.$ in atom $\left.\mathrm{cm}^{-3} \mathrm{~s}\right)$, which is the product of the reaction time $t$ with the time-averaged chlorine radical concentration along the reactor $\langle\mathrm{Cl}\rangle_{t}$

$\frac{\ln \frac{\left[\text { Acet }_{t}\right.}{[\text { Acet }]_{0}}}{-k_{\text {ref }}}=\int_{0}^{t}[\mathrm{Cl}] \mathrm{d} t=\langle\mathrm{Cl}\rangle_{t} \cdot t$

where $[\text { Acet }]_{0}$ and $[\text { Acet }]_{t}$ are the initial and final concentrations of acetone measured by FTIR spectroscopy respectively. As shown in Fig. 2, the chlorine exposure, $\langle\mathrm{Cl}\rangle_{t} \cdot t$, is linearly proportional to $\left[\mathrm{Cl}_{2}\right]$ with a maximum time-averaged chlorine radical concentration of $2.25 \times 10^{9}$ atom $\mathrm{cm}^{-3}$. The ratio $\left[\mathrm{Cl}_{2}\right] /\left[\mathrm{Cl}^{*}\right]$ expresses the photodissociation efficiency and is greater than 3000 , which means that on average $1 \mathrm{Cl}_{2}$ out of 6000 is dissociated by photolysis and produces $2 \mathrm{Cl}^{\circ}$ radicals.

\subsection{Analytical procedure}

\subsubsection{Particle sampling and GC/MS analysis}

At the reactor outlet, the particles are sampled on a PTFE (polytetrafluoroethylene) filter (Millipore FALP, $1.0 \mu \mathrm{m}$, diameter $47 \mathrm{~mm}$ ) for $10 \mathrm{~min}$ in order to collect about $20 \mu \mathrm{g}$ of PA. The filter is then placed in a $1.5 \mathrm{~mL}$ vial and $10 \mu \mathrm{L}$ of a solution containing two internal standards (tetradecane and hexadecane) and $25 \mu \mathrm{L}$ of a commercial mixture $99 \%$ BSTFA $/ 1 \%$ TMCS is deposited directly on the membrane. Quantitative analysis of carboxylic acids by gas chromatography requires derivatization of the $-\mathrm{COOH}$ function. Silylation by BSTFA (N, O-Bis (trimethylsilyl) trifluoroacetamide, $\mathrm{C}_{8} \mathrm{H}_{18} \mathrm{~F}_{3} \mathrm{NOSi}_{2}$ ) has been previously used for the determination of mono- and dicarboxylic acids in samples of atmospheric particles collected on filters (Docherty and Ziemann, 2001; Wang et al., 2009; Zuo et al., 2007; Yu et al., 1998). Trimethylchlorosilane (TMCS) acts as a catalyst by increasing the silyl donor strength of the BSTFA. After finally adding a volume of $1 \mathrm{~mL}$ of dichloromethane, the filter is subjected to $10 \mathrm{~min}$ of sonication. For the product identification, only a volume of $200 \mu \mathrm{L}$ of dichloromethane is added before the sonication. NIST mass spectra database (V2.2) is used for the identification. After the extraction and silylation steps, $1 \mu \mathrm{L}$ of the solution is injected into a GC/MS

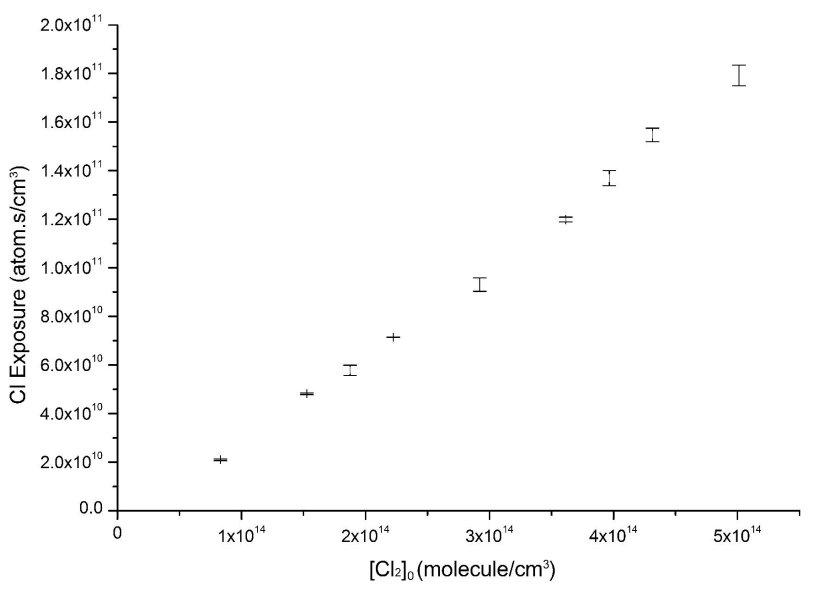

Fig. 2. Chlorine exposure as a function of the initial $\mathrm{Cl}_{2}$ concentration in the reactor. $Q_{\text {tot }}=4.0 \mathrm{~L} \mathrm{~min}^{-1}$ and eight UV lamps are powered. Error bars express the minimum and maximum values of four experiments.

(Perkin-Elmer GC Clarus 680). The chromatographic conditions are as follows: inlet $250^{\circ} \mathrm{C}$; split mode $5 \mathrm{~mL} \mathrm{~min}^{-1}$; constant column flow $1 \mathrm{~mL} \mathrm{~min}^{-1}$; oven temperature $50^{\circ} \mathrm{C}$ for $0.5 \mathrm{~min}$, ramp $+20^{\circ} \mathrm{C} \mathrm{min}^{-1}$ to the final temperature $310^{\circ} \mathrm{C}$. Separation is provided by an Elite-5MS $30 \mathrm{~m}$ long column (diameter $250 \mu \mathrm{m}$ and film thickness $0.5 \mu \mathrm{m}$ ). Identification and quantification is performed on a Clarus 600C mass spectrometer in $70 \mathrm{eV}$ electron impact mode with a source temperature of $180^{\circ} \mathrm{C}$.

The quantification of palmitic acid is done by injecting standard solution of known concentration. The ion fragment corresponding to the silyl group $\mathrm{Si}\left(\mathrm{CH}_{3}\right)_{3}(\mathrm{~m} / z=73)$ is chosen for the quantification of silylated palmitic acid. All samples are injected in triplicates in selected ion monitoring (SIM) mode for the quantification and once in scan mode for identification. The mass of PA particles collected on the filter for 10 min was quantified by GC/MS and compared to the mass concentration measured by the SMPS analysis during the same period. It appears that the mass derived from GC/MS represents $80 \% \pm 10 \%$ of the mass as determined by the SMPS. These measurements have been performed without UV radiations and thus without $\mathrm{Cl}^{\bullet}$ radicals in the AFT. Among the causes that can explain these differences, we can surely mention the following: efficiency of the extraction of palmitic acid before GC/MS analyses; errors from the SMPS analysis, which is a non-absolute technique for mass determination, due to many assumptions introduce in the SMPS data process (shape and density of the particles); and other error sources such as the calibration of the particle counter. 


\subsubsection{FTIR analysis}

Gas-phase analyses were performed by FTIR spectroscopy mainly for the chlorine exposure determination. The FTIR spectra are recorded with an Avatar spectrometer from Thermo Scientific equipped with a $10 \mathrm{~m}$ length multipath cell. Each spectrum is obtained while averaging 100 scans in the $400-4000 \mathrm{~cm}^{-1}$ spectral range with a spectral resolution of $1 \mathrm{~cm}^{-1}$. Background spectra are taken before and after reactivity experiments to make sure that measured products are not stuck on the mirrors of the cell.

\section{Results and discussion}

\subsection{Chlorine reactivity in $\mathrm{N}_{2}$}

\subsubsection{Kinetic measurements}

First, we studied the heterogeneous oxidation of palmitic acid particles by $\mathrm{Cl}$ radicals in an $\mathrm{O}_{2}$-free environment. The classical parameter determined in heterogeneous kinetic measurements is the reactive uptake coefficient $\gamma_{\mathrm{Cl}}$, which is defined as the fraction of $\mathrm{Cl}$ collisions with the particle leading to the loss of $\mathrm{Cl}$ in the gas phase. Since the loss of $\mathrm{Cl}$ is not measured in this experiment, the reaction is monitored through the reactive loss of palmitic acid in the particle-phase $\gamma_{\mathrm{PA}}$. The PA loss rate can be expressed as follows:

$$
\frac{\mathrm{d}[\mathrm{PA}]}{\mathrm{d} t}=-k_{\mathrm{PA}}[\mathrm{Cl}][\mathrm{PA}]
$$

where $k_{\mathrm{PA}}$ is the second-order rate constant of PA with $\mathrm{Cl}\left(\mathrm{cm}^{3}\right.$ molecule $\left.{ }^{-1} \mathrm{~s}^{-1}\right)$. [PA] and [Cl] are the timedependent concentrations of the reactants (molecule $\mathrm{cm}^{-3}$ ). The palmitic loss $\varphi_{\text {loss }}$ (molecule $\mathrm{s}^{-1} \mathrm{~cm}^{-2}$ ) is defined by

$\varphi_{\text {loss }}=\frac{V}{S_{\mathrm{P}}} k_{\mathrm{PA}}[\mathrm{PA}][\mathrm{Cl}]$,

where $S_{\mathrm{P}}$ is the particle surface density $\left(\mathrm{cm}^{2} \mathrm{~cm}^{-3}\right)$ and $V$ the volume of the particle. The flux of collisions $\varphi_{\text {coll }}$ (molecule $\mathrm{s}^{-1} \mathrm{~cm}^{-2}$ ) occurring on the particle surface per second is expressed in the Eq. (5):

$\varphi_{\mathrm{coll}}=\frac{[\mathrm{Cl}] \times \omega_{\mathrm{Cl}}}{4}$,

where $\omega_{\mathrm{Cl}}$ is the mean speed of gas-phase $\mathrm{Cl}\left(\mathrm{cm} \mathrm{s}^{-1}\right)$. The integration of Eq. (3) leads to

$k_{\mathrm{PA}}=\frac{\ln \frac{[\mathrm{PA}]_{0}}{[\mathrm{PA}]_{t}}}{\langle\mathrm{Cl}\rangle_{t} \times t}$.

$[\mathrm{PA}]_{0}$ and $[\mathrm{PA}]_{t}$ are the initial and final concentrations (molecule $\mathrm{cm}^{-3}$ ) of particle-phase $\mathrm{PA}$, respectively, and measured by GC/MS. $\langle\mathrm{Cl}\rangle_{t} \cdot t$ (atom $\mathrm{cm}^{-3} \mathrm{~s}$ ) is the exposure obtained by the reference kinetics measurements and $k_{\mathrm{PA}}$ is experimentally determined from the decay of palmitic acid as a function of the exposure. Moreover, $[\mathrm{PA}]_{0}$ can be replaced in the uptake coefficient expression by

$[\mathrm{PA}]_{0}=\frac{V_{\mathrm{P}} \times \rho_{\mathrm{PA}} \times N_{\mathrm{A}}}{M_{\mathrm{PA}}}$,

where $V_{\mathrm{P}}$ is the particle volume density $\left(\mathrm{cm}^{3} \mathrm{~cm}^{-3}\right), M_{\mathrm{PA}}$ is the molar mass of palmitic acid $\left(M_{\mathrm{PA}}=256 \mathrm{~g} \mathrm{~mol}^{-1}\right), \rho_{\mathrm{PA}}$ is the palmitic acid density $\left(\rho_{\mathrm{PA}}=0.852 \mathrm{~g} \mathrm{~cm}^{-3}\right)$ and $N_{\mathrm{A}}$ is the Avogadro number. Finally, the uptake coefficient $\gamma_{\mathrm{PA}}$ can be expressed as

$\gamma_{\mathrm{PA}}=\frac{\varphi_{\text {loss }}}{\varphi_{\text {coll }}}=\frac{4 \times k_{\mathrm{PA}} \times D_{\text {mean }} \times \rho_{\mathrm{PA}} \times N_{\mathrm{A}}}{\omega_{\mathrm{Cl}} \times 6 \times M_{\mathrm{PA}}}$.

$D_{\text {mean }}$ is the mean surface-weighted diameter of the particle distribution and is calculated by $V_{\mathrm{P}} / S_{\mathrm{P}}=D_{\text {mean }} / 6$ (Smith et al., 2009). The mean particle diameter is determined by SMPS measurements and is assumed to be constant and equal to the initial mean particle diameter. The initial particle diameter has been chosen to determine the uptake coefficient for two main reasons: (1) we measure initial uptake coefficient, and the (2) aged particle real diameter cannot be derived from SPMS data as their density is not known.

The normalized decay of $\left([\mathrm{PA}]_{t} /[\mathrm{PA}]_{0}\right)$ as a function of $\mathrm{Cl}$ exposure is shown in Fig. 3. The decay constant $k_{\mathrm{PA}}$ is obtained from an exponential fit to the experimental measurements for exposure values ranging from 0 to $4 \times 10^{11}$ molecule $\mathrm{cm}^{-3} \mathrm{~s}$.

Using the rate constant $k_{\mathrm{PA}} \quad\left(k_{\mathrm{PA}}=1 \times\right.$ $10^{-11}$ molecule ${ }^{-1} \mathrm{~cm}^{3} \mathrm{~s}^{-1}$ ) obtained from the slope of the exponential fit of kinetic data in Fig. 3, the initial uptake coefficient $\gamma_{\text {PA }}$ has been determined to be equal to $14 \pm 5$ in an oxygen-free environment. Using the model developed by Fuchs and Sutugin (1970), the calculation of the gas-phase diffusion limitation leads to a correction of $10 \%$ for $\gamma$, which is smaller than the total error from the experiment setup. The high value of $\gamma$ means that (1) the heterogeneous reaction of $\mathrm{PA}$ with $\mathrm{Cl}$ radical is very efficient and (2) the secondary chemistry is leading the overall reaction. These results are similar to those of Liu et al. (2011), who reported $\gamma=3$ for the uptake coefficient of chlorine on squalane particles. However, Liu et al. (2011) determined the loss of squalane as a function of the total chlorine radical concentration, while in this study, the loss of palmitic acid is measured as a function of the chlorine radical concentration produced only from the photolysis of $\mathrm{Cl}_{2}$. As a result, the uptake coefficients cannot be strictly compared but both show the importance of secondary chemistry.

By definition, the initial uptake coefficient, when derived from the measurement of the rate loss of the gas-phase oxidant $\mathrm{Cl}_{\mathrm{g}}, \gamma_{\mathrm{Cl}}$, cannot be greater than 1 . Here the uptake coefficient, determined from the rate loss of the condensed phase $\left(\gamma_{\mathrm{PA}}\right)$, is significantly greater than one $\left(\gamma_{\mathrm{PA}}=14 \pm 5\right)$, indicating an efficient secondary heterogeneous chemistry leading the whole reaction. The chain propagation length is the 


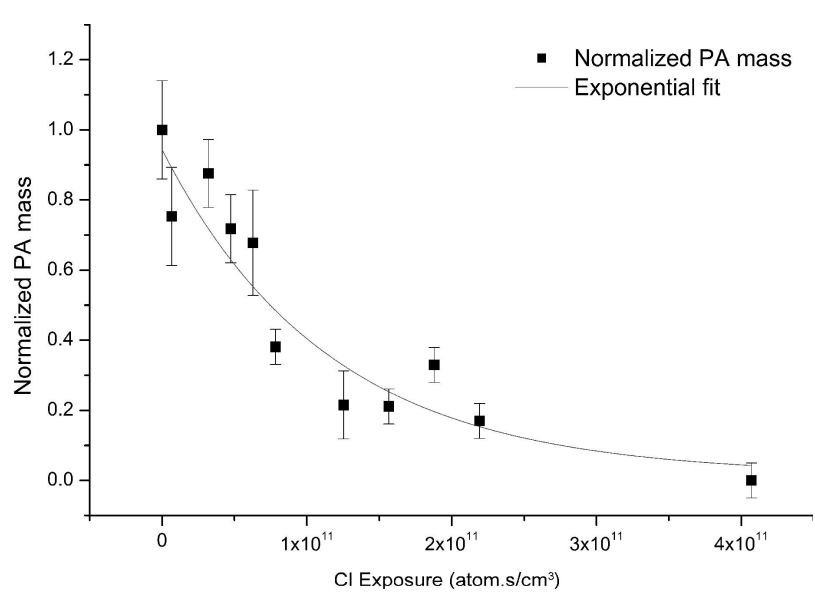

Fig. 3. Normalized mass of PA remaining in the particles collected on filter over $10 \mathrm{~min}$ as a function of the chlorine exposure (squares). Each data point is the mean value obtained from three GC/MS analyses of two particles samples. Error bars represent the minimum and maximum values. The data have been fitted by an exponential function (solid line).

ratio between the number of palmitic acid molecules lost and $\mathrm{Cl}_{\mathrm{g}}$ atoms that react, and corresponds to the ratio $\gamma_{\mathrm{PA}} / \gamma_{\mathrm{Cl}}$. The chain propagation length is at least equal to 14 .

Although the palmitic acid particles are solid, the complete palmitic acid mass can be almost consumed. This behaviour has already been observed for heterogeneous chemistry involving liquid compounds where diffusion in the bulk can be suggested as an explanation for fast refreshing of the surface. In the case of solid particles, this surprising observation is somehow more difficult to discuss. Two hypotheses can be put forward: (1) an efficient volatilization of the products formed at the surface of the particle, or (2) a phase change of the first layers facilitating diffusion or trapping of species within the particle (McNeill et al., 2008; Marcolli et al., 2004; Garton et al., 2000).

\subsubsection{Reaction mechanism}

The high value of the uptake coefficient confirms that the PA consumption is enhanced by secondary chemistry. Liu et al. (2011) proposed a catalytic mechanism which can be adapted to our oxidation process.

$$
\begin{aligned}
& \mathrm{Cl}_{2} \rightarrow \mathrm{Cl}_{\mathrm{g}}^{\cdot}+\mathrm{Cl}_{\mathrm{g}}^{\cdot} \quad \mathrm{Cl}_{2} \text { photolysis } \\
& \mathrm{RH}+\mathrm{Cl}_{\mathrm{g}}^{\circ} \rightarrow \mathrm{R}^{\circ}+\mathrm{HCl} \quad \mathrm{H}-\text { abstraction } \\
& \mathrm{R}^{\bullet}+\mathrm{Cl}_{2} \rightarrow \mathrm{RCl}+\mathrm{Cl}_{\mathrm{p}}^{\bullet} \quad \mathrm{Cl}_{2} \text { addition } \\
& \mathrm{RH}+\mathrm{Cl}_{\mathrm{p}}^{\cdot} \rightarrow \mathrm{R}^{\cdot}+\mathrm{HCl} \quad \text { Second } \mathrm{H}-\text { abstraction } \\
& \mathrm{R}^{\bullet}+\mathrm{Cl}_{\mathrm{p}}^{\circ} \rightarrow \mathrm{RCl} \quad \text { Termination reaction } \\
& \mathrm{R}^{\bullet}+\mathrm{Cl}_{\mathrm{g}}^{\cdot} \rightarrow \mathrm{RCl} \quad \text { Termination reaction } \\
& \mathrm{Cl}^{\bullet}+\mathrm{Cl}^{\bullet}+\mathrm{M} \rightarrow \mathrm{Cl}_{2}+\mathrm{M} \text { Termination reaction }
\end{aligned}
$$

$\mathrm{Cl}^{\circ}$ is defined as a gas-phase $\mathrm{Cl}^{\circ}$ produced from $\mathrm{Cl}_{2}$ photolysis. The initiation Reaction (R2) is the heterogeneous reac- tion between $\mathrm{Cl}^{\circ}$ and particle-phase PA at the surface of the particle producing an alkyl radical $\mathrm{R}^{\circ}$. A chlorine molecule can be added on the $\mathrm{R}^{\circ}$, leading to formation of a chlorinated product and atomic chlorine $\mathrm{Cl}^{\circ} \mathrm{p}$. This chlorine atom is released from the surface of the particle and can easily react with another hydrocarbon. Reactions (R5), (R6), and (R7) are reactions terminating the radical chain propagation. Reaction (R7) could occur heterogeneously via the collision between $\mathrm{Cl}^{\circ}$ and $\mathrm{Cl}^{\circ}$ p but also can take place in the condensed phase and involve two $\mathrm{Cl}^{\circ}$. Such a heterogeneous mechanism has already been observed in previous studies performed either on $\mathrm{NaCl}$ particles (Ciuraru et al., 2011) or on ammonium sulfate particles (Ciuraru et al., 2012). The reaction rate of Reaction (R2) is defined by the uptake coefficient of chlorine on the particle surface $\gamma_{\mathrm{Cl}}$. Reaction (R3) is a source of $\mathrm{Cl}^{\circ}$ allowing the chlorine radical concentration to be renewed; moreover the $\left[\mathrm{Cl}_{2}\right]$ concentration is in excess of $\left[\mathrm{Cl}^{*}\right]\left(\left[\mathrm{Cl}_{2}\right] /\left[\mathrm{Cl}^{*}\right]>3000\right)$.

\subsubsection{Change in the particle size distribution}

The SMPS data indicate that the initial log-normal particle distribution mean diameter shifts from 520 to $405 \mathrm{~nm}$ after a $\mathrm{Cl}$ exposure of $1.25 \times 10^{11}$ molecule $\mathrm{cm}^{-3} \mathrm{~s}$ (see Fig. 4). For this specific exposure, the aerosol mass measured by SMPS decreases by $40 \%$, whereas the GC/MS analysis shows that $80 \%$ of the particle-phase PA is lost. Chlorinated products have a higher molar mass than PA and it is assumed that they remain in the condensed phase, thus changing the density of oxidized particles compared to initial pure PA particles. The oxidized particle diameter cannot therefore be rigorously determined because the particle diameter is obtained from electrical mobility of the particle, which depends on their density. Assuming that the change of the mean diameter is only due to the density variation would indicate that the particle density would have increased from 0.852 to 1.850 . This value seems too high for an organic compound and suggests that the mean diameter change is also due to volatilization of products. Consequently, the initial mean surface-weighted particle diameter is considered in this following kinetic study.

\subsubsection{Particulate-phase product identification}

Evidence of presence of monochlorinated palmitic acid is found in the mass spectra. Fragments with $m / z=362$ and 364 are detected and correspond to the parent peaks of the silylated monochlorinated palmitic acid $\left(\mathrm{C}_{15} \mathrm{H}_{30} \mathrm{Cl}-\mathrm{COO}-\mathrm{Si}-\right.$ $\left.\left(\mathrm{CH}_{3}\right)_{3}\right)$ with a characteristic pattern for the $m / z=35$ and 37 isotopic relative abundances of chlorine. In those mass spectra, the presence of the peak $m / z=117$ (corresponding to $\left.\mathrm{COO}-\mathrm{Si}-\left(\mathrm{CH}_{3}\right)_{3}\right)$ shows that the carboxylic acid function has not been modified and the chlorine atom has not been added on the oxygen atom. Because the hydrogen abstraction by chlorine can occur at 17 different sites, several monochlorinated products are detected instead of one single product. 


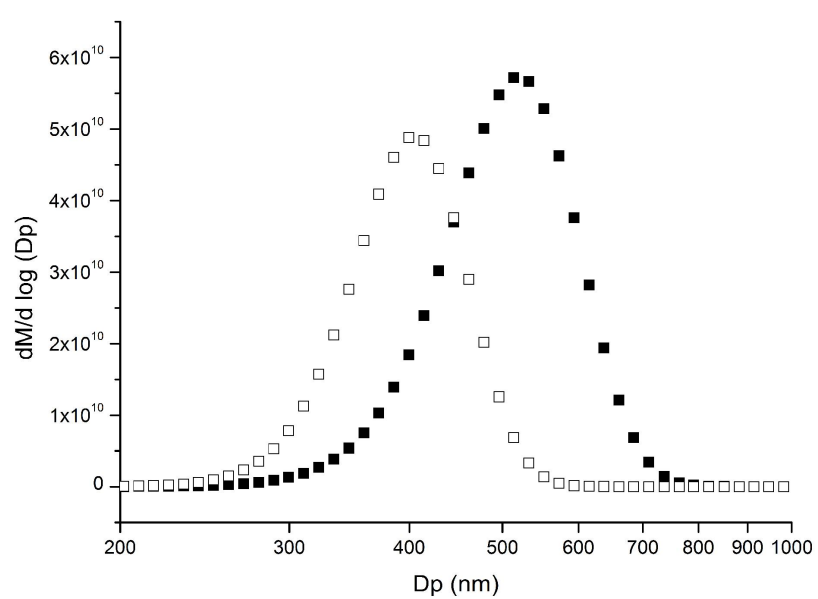

Fig. 4. Mass-weighted particle distribution (normalized $\mu \mathrm{g} \mathrm{m}^{-3}$ ) of PA particles before (filled squares) and after (open squares) a chlorine exposure of $1.25 \times 10^{11}$ atom $\mathrm{cm}^{-3} \mathrm{~s}$. Each distribution is an average of eight measurements.

Dichlorinated palmitic acid molecules are also detected in the sampled particles. The formation of different constitutional isomers induces much smaller peaks than the monochlorinated ones. The mass spectra of those species show that the $m / z=396,398$, and $400 \mathrm{amu}$, indicating the presence of the parent peak of $\mathrm{C}_{15} \mathrm{H}_{29} \mathrm{Cl}_{2}$ - $\mathrm{COO}-\mathrm{Si}-\left(\mathrm{CH}_{3}\right)_{3}$ with the natural abundance of chlorine atoms. The mass spectra of those species indicate the presence of the silylated monochlorinated palmitic acid fragment $(\mathrm{m} / z=362$ and 364) and also the silylated carboxylic acid function. Polychlorinated palmitic acid molecules such as trichlorinated palmitic acid molecules and more are highly suspected but the signal-to-noise ratios are too low to get unambiguous identifications.

\subsection{Chlorine reactivity in the presence of $\mathrm{O}_{2}$}

\subsubsection{Kinetic measurements}

The effect of oxygen on the heterogeneous reactivity between $\mathrm{Cl}^{\circ}$ atoms and PA particles has been explored by using a $\mathrm{N}_{2} / \mathrm{O}_{2}$ mixture $(80 \% / 20 \%)$ as a carrier gas for the aerosol flow. The particle-phase PA decay is much slower when oxygen is added in the chemical system compared to the measurements without $\mathrm{O}_{2}$ (see Fig. 5). The uptake coefficient of $\gamma_{\mathrm{PA}}=3$ has been determined and shows that the catalytic secondary reactions still govern the decay of PA but the propagation length of the catalytic reactions is reduced. The decrease of the uptake coefficient as a function of the oxygen concentration has been previously observed by Liu et al. (2011) in the heterogeneous oxidation of squalane $(\mathrm{Sq})$ by chlorine radicals. The secondary chemistry involving $\mathrm{Cl}_{2}$ is considered as insignificant because the ratio between $\mathrm{O}_{2}$ and $\mathrm{Cl}_{2}$ concentrations is greater than 1000 . In the presence of

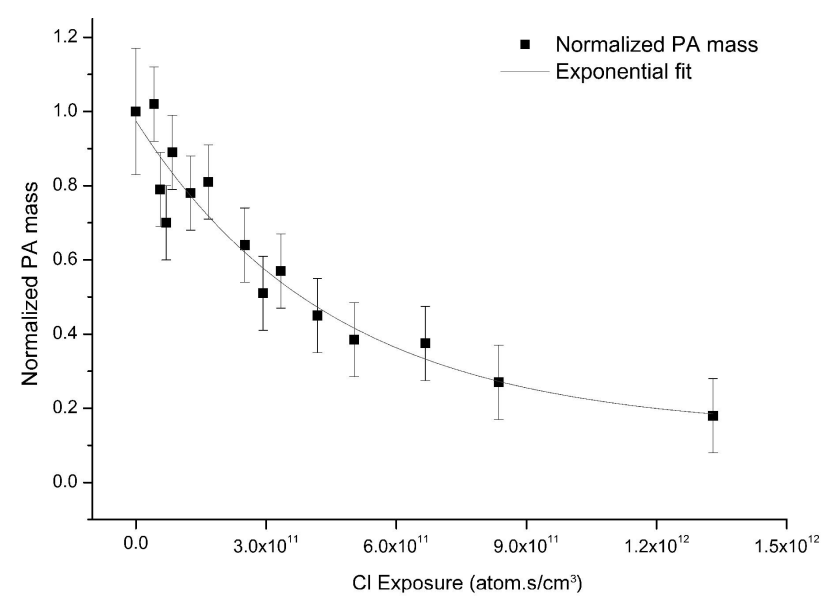

Fig. 5. Normalized mass of PA remaining in the particles as a function of the chlorine exposure in the presence of oxygen (squares) and the corresponding exponential fit (solid line).

$\mathrm{O}_{2}$, a new reaction $\left(\mathrm{R}^{\bullet}+\mathrm{O}_{2}\right)$ competes with Reaction (R3), leading to the formation of an alkyl peroxy radical instead of a chlorinated radical.

\subsubsection{Particulate product identification}

The product identification was performed after the derivatization step by collecting the particles at the AFT outlet over 30 min (see Fig. 6). We were not able to identify any products on non-derivatized samples.

The main identified products are dicarboxylic and oxocarboxylic acids and confirm the observations by McNeill et al. (2008), where oxocarboxylic acids were detected. This new study allows for identification and speciation of dicarboxylic acids and oxocarboxylic acids. Oxocarboxylic acids detected are oxopentanoic, oxohexanoic, and oxoheptanoic acid.

The identification shows that the oxocarboxylic acids are produced on shorter carbon chain length than the palmitic acid but the $\mathrm{C}=\mathrm{O}$ function position could not be determined in the mass spectra. Moreover, we suppose that several isomers of oxocarboxylic acids can be produced and that they may have not been separated with the gas chromatography conditions. Dicarboxylic acids have been detected from the propanedioic acid (C3) to octanedioic acid (C8). The normalized yields (Fig. 7) are calculated from the ratio of a specific dicarboxylic acid chromatographic peak area over the $\mathrm{C} 3$ dicarboxylic acid peak area. Those ratios are only for a comparison purpose and assume that the response coefficients are equal. The normalized yields are much higher for C3 and C4 dicarboxylic acids (Fig. 7). For that reason, oxalic acid is suspected to be produced but it was not detected under our analytical conditions.

Products with hydroxyl functions were also detected but their formal identification cannot be guaranteed without doubt. Those products are hydroxyethanoic acid, 


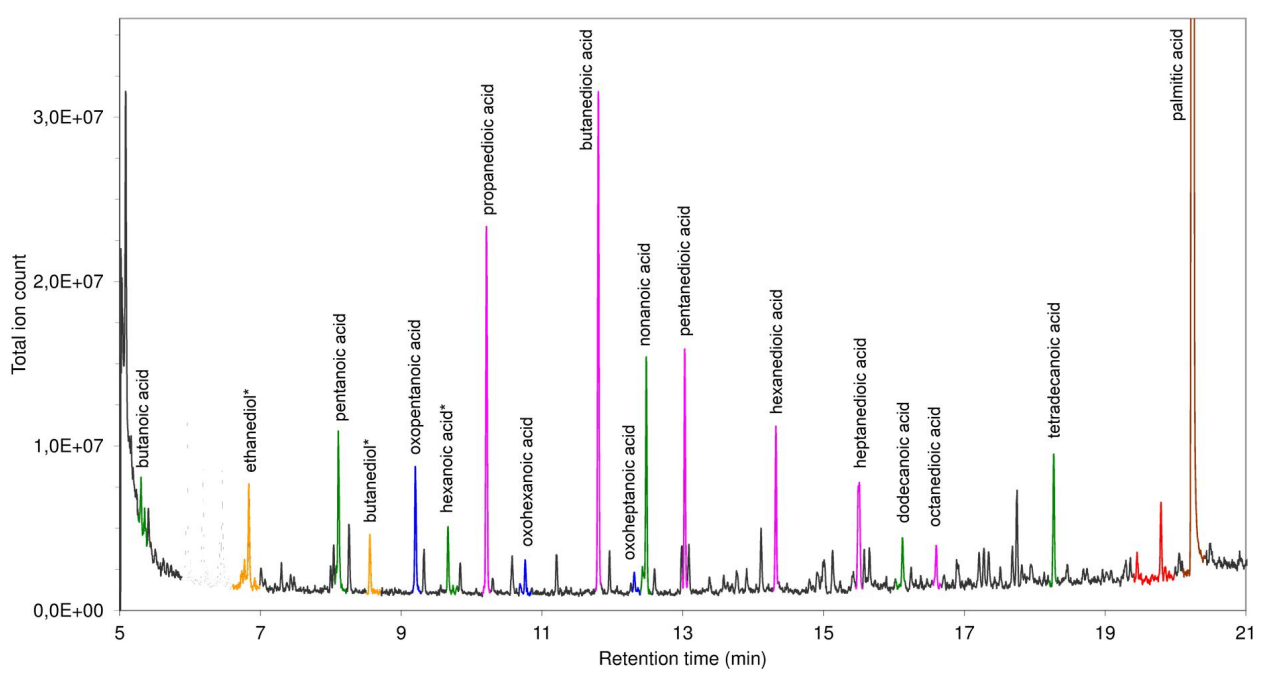

Fig. 6. Chromatogram of the silylated products from the $\mathrm{Cl}$-initiated oxidation of $\mathrm{PA}$ in the presence of $\mathrm{O}_{2}\left({ }^{*}\right.$ uncertain identification).

hydroxypropanoic acid, and several diols which are consistent with the formation of hydroxyacid proposed by McNeill et al. (2008). Monocarboxylic acids were also detected in much lower quantities. Moreover, the gas-phase products $\mathrm{HCl}, \mathrm{CO}_{2}$ and $\mathrm{CO}$ have been clearly identified by FTIR spectroscopy by means of their characteristic fundamental bands and well-known IR spectra in the case of the maximum chlorine exposure. However the measurement of the integrated area of each band, with enough precision to performed quantification, was only possible in the case of maximum exposure (i.e. eight $\mathrm{UV}$ lamps and maximum flux of $\mathrm{Cl}_{2}$ in the AFT). For lower $\mathrm{Cl}^{\bullet}$ exposure the signal-to-noise ratio was not sufficient, even when spectra were co-added over $10 \mathrm{~min}$. Not only the formation kinetic of $\mathrm{HCl}$ but also that of $\mathrm{CO}$ and $\mathrm{CO}_{2}$ would be an important result, but due to poor confidence in the results, we could not derive any kinetic information.

\subsubsection{Chemical mechanism}

We propose a reaction mechanism (see Fig. 8) for the radical initiated oxidation of PA particles adapted from the mechanism presented by George and Abbatt (2010). We have intentionally reduced the reaction mechanism to the observed pathways based on the products identified by GC/MS. Because no relative carbon yields are suggested in our study, we cannot determine which reaction path dominates. We have chosen to show the mechanism with an $\mathrm{H}$ abstraction on the $\beta$ position of the carboxylic function. This is for a better understanding of the mechanism and does not necessarily correspond to a preferential site of $\mathrm{H}$ abstraction.

As in the case of the experiments without $\mathrm{O}_{2}$, the first step leads to the abstraction of a hydrogen atom by a $\mathrm{Cl}^{*}$ radical from the aliphatic chain $(\mathrm{R} 1)$ or from the carboxylic acid group (R'1) (Smith and Ravishankara, 2002; Singleton et al., 1989). Reaction (R8) is the internal recombination of $\mathrm{RCOO}^{\bullet}$ to form $\mathrm{CO}_{2}$ and the $\mathrm{R}^{\bullet}$ radical. Reaction (R9) leads to the regeneration of palmitic acid. The radical $\mathrm{C}_{15} \mathrm{H}_{31}{ }^{\circ}$ formed on Reaction (R8) will be oxidized to an alcohol, aldehyde or ultimately to a carboxylic acid.

Reaction ( $\mathrm{R} 11$ ) shows the recombination of $\mathrm{RO}_{2}{ }^{\cdot}$ with $\mathrm{RO}_{2}{ }^{\bullet}$ to form an aldehyde and an alcohol. Reaction (R12) leads to the formation of an alkoxy radical by recombination of two $\mathrm{RO}_{2}{ }^{\circ}$ radicals. This radical leads, via Reaction (R13), to the formation of a C16 oxocarboxylic acid with the carbonyl group on the position of the initial $\mathrm{H}$ abstraction. The alkoxy radical recombines by $\mathrm{C}-\mathrm{C}$ scission via two pathways, Reactions (R14a) and (R14b), to form shorter chain oxocarboxylic acids and ketones. Formation of dicarboxylic acid is proposed in Reaction (R15) to occur from an oxocarboxylic acid via $\mathrm{H}$ abstraction on the carbonyl group and further recombination with a second peroxy radical.

The current study suggests that the products can also be formed by any radical-initiated oxidation of carboxylic acids. Moreover, the proposed mechanism is valid independently of the radical $\left(\mathrm{OH}^{\bullet}\right.$ or $\left.\mathrm{Cl}^{\bullet}\right)$ that is involved in the $\mathrm{H}$ abstraction.

\subsubsection{Discussion of previous results}

The values of $\gamma$ determined in this work for $\mathrm{Cl}^{\bullet}+\mathrm{PA}$ are significantly higher than for previously published paper for the chemical system $\mathrm{Cl}^{\circ}+$ squalane $(\mathrm{Sq})$ and $\mathrm{Cl}^{\circ}+$ DOS (dioctyl sebacate) heterogeneous reactions (Table 1). In the presence of oxygen, the reaction is still dominated by secondary chemistry but the propagation chain length is smaller than in the absence of $\mathrm{O}_{2}$ because there is no regeneration of $\mathrm{Cl}^{\circ}$. In our conditions, the uptake coefficient decreases by a factor of five when oxygen is added to the chemical system. This result confirms the observation made by Liu et al. (2011) 
Table 1. Summary of measured uptake coefficients for heterogeneous reaction systems involving organic aerosol with the radical species $\mathrm{OH}^{\bullet}$ and $\mathrm{Cl}^{\bullet}$.

\begin{tabular}{|c|c|c|}
\hline Uptake coefficient & $\mathrm{OH}$ & $\mathrm{Cl}$ \\
\hline Squalane $\left(\mathrm{C}_{30} \mathrm{H}_{62}\right)$ & $\begin{array}{l}\gamma_{\mathrm{SQ}}=0.3 \\
(\text { Smith et al., 2009) }\end{array}$ & $\begin{array}{l}\gamma_{\mathrm{SQ}}=3 \text { in } \mathrm{N}_{2}(\text { Liu et al., 2011) } \\
\gamma_{\mathrm{SQ}}=0.6 \text { in } \mathrm{N}_{2} / \mathrm{O}_{2} \text { (Liu et al., 2011) }\end{array}$ \\
\hline $\begin{array}{l}\text { DOS } \\
\left(\left(\mathrm{CH}_{2}\right)_{8}\left(\mathrm{COOC}_{8} \mathrm{H}_{17}\right)_{2}\right)\end{array}$ & $\begin{array}{l}\text { YDOS }=2.0 \\
(\text { Hearn and Smith, 2006) }\end{array}$ & $\begin{array}{l}\gamma_{\mathrm{DOS}}=1.7 \text { in } \mathrm{N}_{2} / \mathrm{O}_{2} \\
(\text { Hearn et al., 2007) }\end{array}$ \\
\hline $\begin{array}{l}\text { Palmitic acid } \\
\left(\mathrm{C}_{16} \mathrm{H}_{32} \mathrm{O}_{2}\right)\end{array}$ & $\begin{array}{l}\gamma_{\mathrm{PA}}=0.3 \\
(\mathrm{McNeill} \text { et al., 2008) }\end{array}$ & $\begin{array}{l}\left.0.1<\gamma_{\mathrm{Cl}}<1 \text { (Ciuraru, } 2010\right) \\
\gamma_{\mathbf{P A}}=\mathbf{1 4} \pm \mathbf{5} \text { in } \mathbf{N}_{\mathbf{2}} \text { (this work) } \\
\gamma_{\mathbf{P A}}=\mathbf{3} \pm \mathbf{1} \text { in } \mathbf{N}_{\mathbf{2}} / \mathbf{O}_{\mathbf{2}} \text { (this work) }\end{array}$ \\
\hline
\end{tabular}

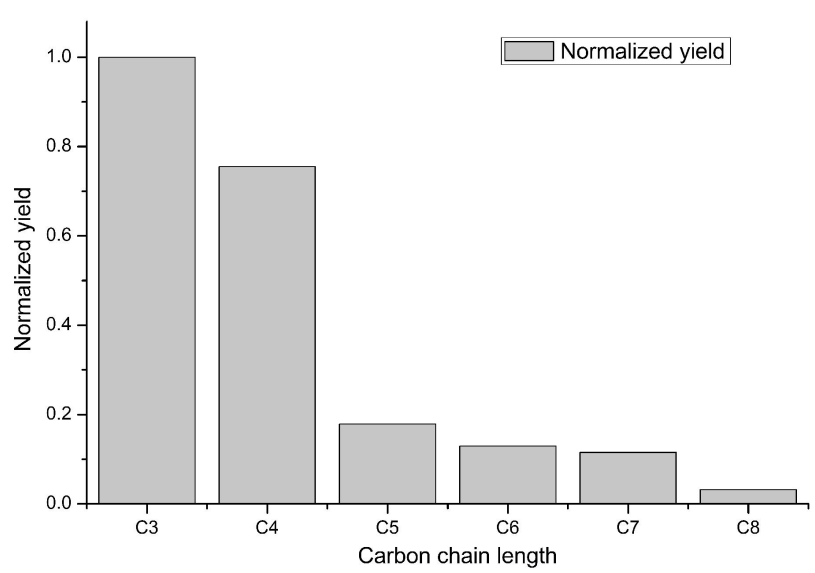

Fig. 7. Normalized yields of the detected dicarboxylic acids as a function of the carbon chain length.

for squalane reactivity in the presence or absence of $\mathrm{O}_{2}$. The study of Hearn and Smith (2008) reports the opposite result, where the rate of DOS loss is faster in the presence of oxygen.

These comparisons have to be made while keeping in mind these following aspects:

- The chemical formulae of the molecules are quite different. In the case of palmitic acid (PA), the molecule exhibits a linear carbon chain with a terminal acid function contrary to DOS and squalane. As secondary chemistry is highlighted for each heterogeneous reaction, the rate of propagation of these chemical reactions should be strongly dependent on the chemical formula.

- PA is a solid, while squalane and DOS are liquid. Even if detailed chemical mechanisms in the condensed phase are still unclear, the rate of elementary processes might be different for solid and liquid.

- The experimental determination of the uptake coefficient was not performed with the exact same methodology. In previous studies the chlorine exposure, $\left(\left\langle\mathrm{Cl}^{\circ}\right\rangle t\right)$, was measured using reference kinetics by introducing the reference compound (2-butanone or acetone) in the mixed phase. For this, it is assumed that the atomic chlorine produced by the Reaction (R3) $\left(\mathrm{R}^{\cdot}+\mathrm{Cl}_{2} \rightarrow \mathrm{RCl}+\mathrm{Cl}_{\mathrm{p}}^{*}\right)$ stays in the liquid particulate phase and never returns to the gas phase. Thus the loss of the reference compound is only due to reaction with $\mathrm{Cl}$ produced by the photolysis of $\mathrm{Cl}_{2}$. However, for the case of solid particles (PA), we have made the assumption that a fraction of chlorine atoms from the Reaction (R3) could return to the gas phase, and it reacts with the reference compound (acetone). For this reason, we decided to measure the chlorine exposure during an independent experiment where only acetone and $\mathrm{Cl}_{2}$ were introduced in the AFT, so the atomic chlorine exposure is assumed as the chlorine radicals generated by the photolysis of $\mathrm{Cl}_{2}$ only. While chlorine exposure used in our study is in the range of the previous cited works, the contact time in the AFT is significantly different: $3 \mathrm{~s}$ for $\mathrm{Cl}^{\bullet}+$ DOS system and $180 \mathrm{~s}$ for our work. But recent results (Renbaum and Smith, 2011) show that radical concentration and time are interchangeable parameters only if the precursor concentrations are the same. These discrepancies with previous studies can explain at least part of our higher uptake values.

\section{Conclusions and atmospheric implications}

Kinetic studies have been performed to measure the uptake coefficient of chlorine atoms on palmitic acid particles as a function of chlorine exposure formed by photolysis of $\mathrm{Cl}_{2}$. The uptake coefficient has been derived from two experimental conditions (with and without $\mathrm{O}_{2}$ ) by measuring the palmitic acid lost from the particle phase as a function of the chlorine exposure. First, we have performed these experiments in an oxygen-free environment. In this case, the uptake coefficient $\gamma_{\mathrm{PA}}$ is estimated to be $\gamma=14 \pm 5$. Secondly, we determined the uptake coefficient in a $\mathrm{N}_{2} / \mathrm{O}_{2}$ mixture 

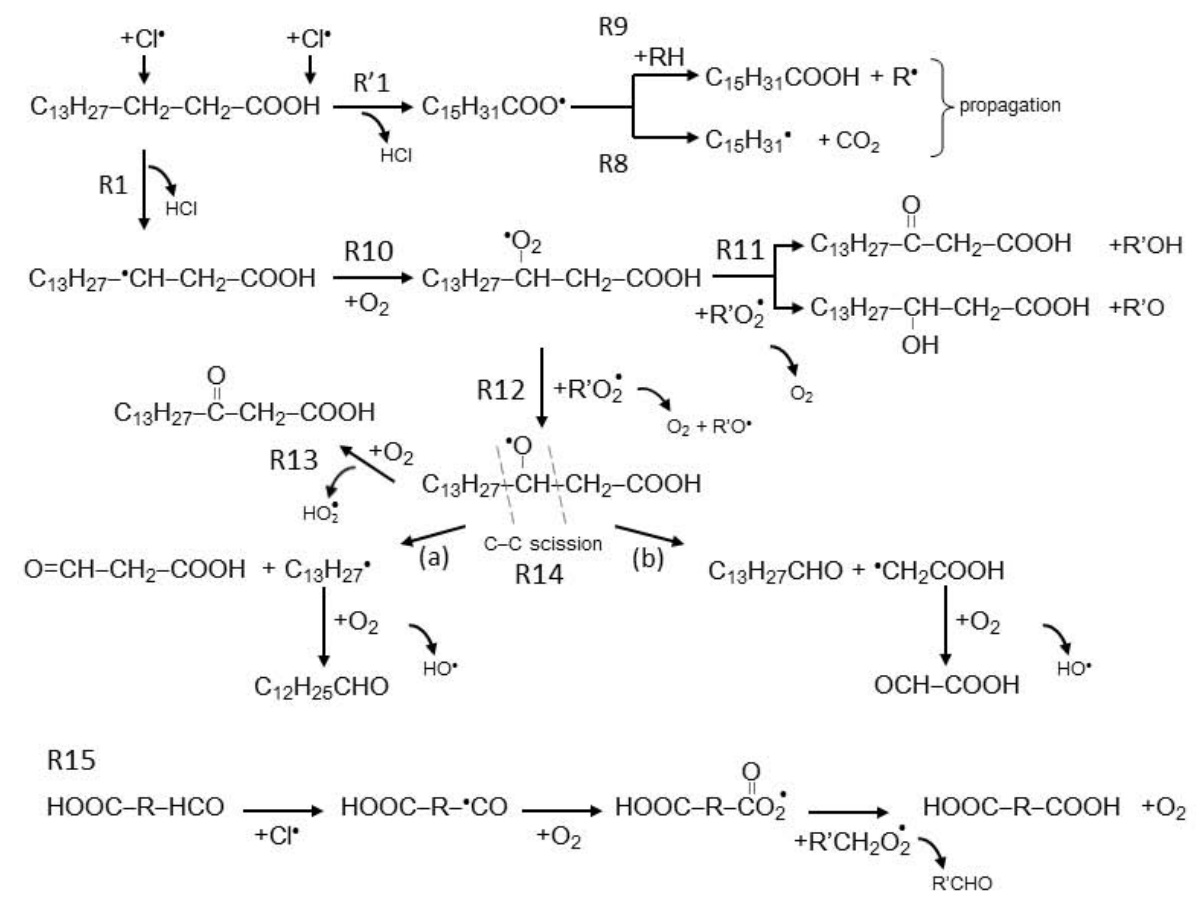

Fig. 8. Reaction mechanism for the chlorine-radical-initiated oxidation of palmitic acid in the presence of $\mathrm{O}_{2}$.

(80/20). It appears that palmitic acid loss rate as a function of the chlorine exposure is lower and $\gamma_{\mathrm{PA}}=3 \pm 1$. It must be considered that the chlorine exposure has been defined as the exposure to the chlorine atom formed only by photolysis of $\mathrm{Cl}_{2}$ and measured during separate experiments. Contrariwise, in the work of Hearn et al. (2007) and Liu et al. (2011), reference kinetics were performed simultaneously with the particle oxidation considering then the chlorine atoms formed by the photolysis but also those formed as products of $\mathrm{Cl}_{2}$ dissociation due to reactivity with $\mathrm{R}^{\cdot}$ radicals. The uptake coefficient determined in those studies cannot be compared directly with the uptake coefficients measured in this work. Under the conditions in this study, their uptake coefficient would have been greater. However, the general behaviour is similar: (1) the uptake coefficient variation is a function of $\mathrm{O}_{2}$ concentration and (2) the uptake coefficient greater than 1 is explained by a secondary chemistry involving radicals $\mathrm{R}^{\circ}$.

The heterogeneous reactivity experiments we performed without $\mathrm{O}_{2}$ reveal (1) an important secondary chemistry where $\mathrm{Cl}_{2}$ is involved and that (2) monochlorinated and polychlorinated compounds are formed with up to four chlorine atoms.

We have observed the formation of $\mathrm{HCl}, \mathrm{CO}$, and $\mathrm{CO}_{2}$ in the gas phase, while in the particle phase, oxocarboxylic acids and dicarboxylic acids are detected. Alcohols and monocarboxylic acids were also detected but with no certain identification of molecular formula. Dicarboxylic and oxocarboxylic acids have been measured in the particulate matter by several field measurement campaigns (Kawamura and Gagosian, 1987, 1990; Kawamura and Ikushima, 1993; Mochida et al., 2002; Kawamura and Yasui, 2005; Wang et al., 2006; Kundu et al., 2010; Pavuluri et al., 2010; Hegde and Kawamura, 2012; Mkoma and Kawamura, 2013) under various environmental conditions (urban, costal, remote marine, remote continental). The presence of oxocarboxylic acids is generally explained by biomass combustion and the aging of primary organic matter (Kawamura and Gagosian, 1987, 1990; Kawamura and Yasui, 2005; Kundu et al., 2010; Pavuluri et al., 2010; Hegde and Kawamura, 2012; Mkoma and Kawamura, 2013). In this study, we observed that the concentration of dicarboxylic acids seemed to decrease with the carbon chain length. Similar distributions of dicarboxylic acids have been observed several times in ambient particulate matter during field measurement campaigns (Kawamura and Yasui, 2005; Kundu et al., 2010; Pavuluri et al., 2010; Hegde and Kawamura, 2012; Mkoma and Kawamura, 2013). Those studies correlate the presence of dicarboxylic acids with the oxidation of fatty acids and show that oxalic acid is the main dicarboxylic acid regardless of the origin of the analysed samples. The conclusions of those studies suggest that a large amount of oxalic acid mass could have been formed in our experimental system although it has not been detected.

Finally, we have highlighted that there is a significant fragmentation and functionalization of the fatty acids by oxidation initiated by radicals. This leads to the volatilization of oxygenated low-molecular-weight organic compounds in the atmosphere. Moreover, the functionalization of the primary 
organic matter leads to the formation of more polar compounds at the surface of the particle and suggests a modification of the hygroscopic properties of the particle. As fatty acids are the most abundant identified organic compounds in the marine aerosols, the aging process of those particles via radical-initiated chemistry may facilitate cloud droplet activation (Westervelt et al., 2012). Finally, oxidation of the organic matter changes the chemical and the physical properties of not only the surface but also of the bulk of the particles, which in turn can affect their ability to absorb or to diffuse the visible solar radiation as well as the thermal IR radiation. Furthermore, more scientific work has to be done in order to better characterize and quantify the role of the aging processes of the organic particles on the atmospheric radiative transfer.

Acknowledgements. The laboratory is part of the IRENI Institute (Institut de Recherche en ENvironnement Industriel), which is financed by the Nord-Pas de Calais regional council and the European Regional Development Fund (ERDF). The CaPPA project (Chemical and Physical Properties of the Atmosphere) is funded by the French National Research Agency (ANR) through the PIA (Programme d'Investissement d'Avenir) under contract ANR-11-LABX-005-01. The authors address many thanks to anonymous referees for their comments and suggestions.

Edited by: B. Ervens

\section{References}

Barger, W. R. and Garrett, W. D.: Surface Active Organic Material in Air Over the Mediterranean and Over the Eastern Equatorial Pacific, J. Geophys. Res., 81, 3151-3157, doi:10.1029/JC081i018p03151, 1976.

Cavalli, F., Facchini, M. C., Decesari, S., Mircea, M., Emblico, L., Fuzzi, S., Ceburnis, D., Yoon, Y. J., O’Dowd, C. D., Putaud, J. P., and Dell'Acqua, A.: Advances in characterization of size-resolved organic matter in marine aerosol over the North Atlantic, J. Geophys. Res., 109, D24215, doi:10.1029/2004jd005137, 2004.

Ciuraru, R.: Étude de la réactivite du chlore atomique avec des particules d'aérosols d'intérêt atmosphérique, 2010.

Ciuraru, R., Gosselin, S., Visez, N., and Petitprez, D.: Heterogeneous reactivity of chlorine atoms with sodium chloride and synthetic sea salt particles, Phys. Chem. Chem. Phys., 13, 1946019470, 2011.

Ciuraru, R., Gosselin, S., Visez, N., and Petitprez, D.: Heterogeneous reactivity of chlorine atoms with ammonium sulfate and ammonium nitrate particles, Phys. Chem. Chem. Phys., 14, 4527-4537, 2012.

Docherty, K. S. and Ziemann, P. J.: On-line, inlet-based trimethylsilyl derivatization for gas chromatography of mono- and dicarboxylic acids, Journal of Chromatography A, 921, 265-275, doi:10.1016/s0021-9673(01)00864-0, 2001.

Donaldson, D. J. and Vaida, V.: The Influence of Organic Films at the Air-Aqueous Boundary on Atmospheric Processes, Chem. Rev., 106, 1445-1461, doi:10.1021/cr040367c, 2006.
Ellison, G. B., Tuck, A. F., and Vaida, V.: Atmospheric processing of organic aerosols, J. Geophys. Res., 104, 11633-11641, doi:10.1029/1999jd900073, 1999.

Facchini, M. C., Rinaldi, M., Decesari, S., Carbone, C., Finessi, E., Mircea, M., Fuzzi, S., Ceburnis, D., Flanagan, R., and Nilsson, E. D.: Primary submicron marine aerosol dominated by insoluble organic colloids and aggregates, Geophys. Res. Lett., 35, L17814, doi:10.1029/2008GL034210, 2008.

Fine, P. M., Cass, G. R., and Simoneit, B. R.: Chemical characterization of fine particle emissions from fireplace combustion of woods grown in the northeastern United States, Environ. Sci. Technol., 35, 2665-2675, 2001.

Fuchs, N. and Sutugin, A.: High-dispersed aerosols, Ann Arbor Science Publishers, 1970.

Garton, D. J., Minton, T. K., Alagia, M., Balucani, N., Casavecchia, P., and Volpi, G. G.: Comparative dynamics of $\mathrm{Cl}(\mathrm{P})$ and $\mathrm{O}$ (P) interactions with a hydrocarbon surface, J. Chem. Phys., 112, 5975, doi:10.1063/1.481170, 2000.

George, I. J. and Abbatt, J. P. D.: Heterogeneous oxidation of atmospheric aerosol particles by gas-phase radicals, Nat. Chem., 2, 713-722, 2010.

George, I. J., Vlasenko, A., Slowik, J. G., Broekhuizen, K., and Abbatt, J. P. D.: Heterogeneous oxidation of saturated organic aerosols by hydroxyl radicals: uptake kinetics, condensed-phase products, and particle size change, Atmos. Chem. Phys., 7, 4187-4201, doi:10.5194/acp-7-4187-2007, 2007.

Gogou, A. I., Apostolaki, M., and Stephanou, E. G.: Determination of organic molecular markers in marine aerosols and sediments: one-step flash chromatography compound class fractionation and capillary gas chromatographic analysis, Journal of Chromatography A, 799, 215-231, doi:10.1016/s0021-9673(97)01106-0, 1998.

Hardy, J. T.: The sea surface microlayer: Biology, chemistry and anthropogenic enrichment, Prog. Oceanogr., 11, 307-328, doi:10.1016/0079-6611(82)90001-5, 1982.

He, L.-Y., Hu, M., Huang, X.-F., Yu, B.-D., Zhang, Y.-H., and Liu, D.-Q.: Measurement of emissions of fine particulate organic matter from Chinese cooking, Atmos. Environ., 38, 6557-6564, doi:10.1016/j.atmosenv.2004.08.034, 2004.

He, L.-Y., Hu, M., Huang, X.-F., Zhang, Y.-H., and Tang, X.-Y.: Seasonal pollution characteristics of organic compounds in atmospheric fine particles in Beijing, Sci. Total Environ., 359, 167176, 2006.

Hearn, J. D. and Smith, G. D.: A mixed-phase relative rates technique for measuring aerosol reaction kinetics, Geophys. Res. Lett., 33, L17805, doi:10.1029/2006g1026963, 2006.

Hearn, J. D., Renbaum, L. H., Wang, X., and Smith, G. D.: Kinetics and products from reaction of $\mathrm{Cl}$ radicals with dioctyl sebacate (DOS) particles in $\mathrm{O}_{2}$ : a model for radical-initiated oxidation of organic aerosols, Phys. Chem. Chem. Phys., 9, 4803-4813, 2007.

Hegde, P. and Kawamura, K.: Seasonal variations of water-soluble organic carbon, dicarboxylic acids, ketocarboxylic acids, and $a$ dicarbonyls in Central Himalayan aerosols, Atmos. Chem. Phys., 12, 6645-6665, doi:10.5194/acp-12-6645-2012, 2012.

Kawamura, K. and Gagosian, R. B.: Implications of [omega]oxocarboxylic acids in the remote marine atmosphere for photooxidation of unsaturated fatty acids, Nature, 325, 330-332, 1987.

Kawamura, K. and Gagosian, R. B.: Mid-chain ketocarboxylic acids in the remote marine atmosphere: Distribution patterns and pos- 
sible formation mechanisms, J. Atmos. Chem., 11, 107-122, doi:10.1007/bf00053670, 1990.

Kawamura, K. and Ikushima, K.: Seasonal changes in the distribution of dicarboxylic acids in the urban atmosphere, Environ. Sci. Technol., 27, 2227-2235, doi:10.1021/es00047a033, 1993.

Kawamura, K. and Yasui, O.: Diurnal changes in the distribution of dicarboxylic acids, ketocarboxylic acids and dicarbonyls in the urban Tokyo atmosphere, Atmos. Environ., 39, 1945-1960, doi:10.1016/j.atmosenv.2004.12.014, 2005.

Keene, W. C., Maring, H., Maben, J. R., Kieber, D. J., Pszenny, A. A., Dahl, E. E., Izaguirre, M. A., Davis, A. J., Long, M. S., Zhou, X., Smoydzin, L., and Sander, R.: Chemical and physical characteristics of nascent aerosols produced by bursting bubbles at a model air-sea interface, J. Geophys. Res., 112, D21202, doi:10.1029/2007JD008464, 2007.

Kundu, S., Kawamura, K., Andreae, T. W., Hoffer, A., and Andreae, M. O.: Molecular distributions of dicarboxylic acids, ketocarboxylic acids and a-dicarbonyls in biomass burning aerosols: implications for photochemical production and degradation in smoke layers, Atmos. Chem. Phys., 10, 2209-2225, doi:10.5194/acp-10-2209-2010, 2010.

Lide, D. R.: CRC Handbook of Chemistry and Physics 2004-2005: A Ready-Reference Book of Chemical and Physical Data, CRC press, 2004.

Liu, C.-L., Smith, J. D., Che, D. L., Ahmed, M., Leone, S. R., and Wilson, K. R.: The direct observation of secondary radical chain chemistry in the heterogeneous reaction of chlorine atoms with submicron squalane droplets, Phys. Chem. Chem. Phys., 13, 8993-9007, 2011.

Marcolli, C., Luo, B., and Peter, T.: Mixing of the organic aerosol fractions: Liquids as the thermodynamically stable phases, J. Phys. Chem. A, 108, 2216-2224, 2004.

Marty, J. C., Saliot, A., Buat-Ménard, P., Chesselet, R., and Hunter, K. A.: Relationship Between the Lipid Compositions of Marine Aerosols, the Sea Surface Microlayer, and Subsurface Water, J. Geophys. Res., 84, 5707-5716, doi:10.1029/JC084iC09p05707, 1979.

McNeill, V. F., Yatavelli, R. L. N., Thornton, J. A., Stipe, C. B., and Landgrebe, O.: Heterogeneous $\mathrm{OH}$ oxidation of palmitic acid in single component and internally mixed aerosol particles: vaporization and the role of particle phase, Atmos. Chem. Phys., 8, 5465-5476, doi:10.5194/acp-8-5465-2008, 2008.

Mkoma, S. L. and Kawamura, K.: Molecular composition of dicarboxylic acids, ketocarboxylic acids, a-dicarbonyls and fatty acids in atmospheric aerosols from Tanzania, East Africa during wet and dry seasons, Atmos. Chem. Phys., 13, 2235-2251, doi:10.5194/acp-13-2235-2013, 2013.

Mochida, M., Kitamori, Y., Kawamura, K., Nojiri, Y., and Suzuki, K.: Fatty acids in the marine atmosphere: Factors governing their concentrations and evaluation of organic films on sea-salt particles, J. Geophys. Res., 107, 4325, doi:10.1029/2001jd001278, 2002.

Moise, T. and Rudich, Y.: Uptake of $\mathrm{Cl}$ and $\mathrm{Br}$ by organic surfaces - A perspective on organic aerosols processing by tropospheric oxidants, Geophys. Res. Lett., 28, 4083-4086, doi:10.1029/2001g1013583, 2001.

Nolte, C. G., Schauer, J. J., Cass, G. R., and Simoneit, B. R.: Highly polar organic compounds present in wood smoke and in the ambient atmosphere, Environ. Sci. Technol., 35, 1912-1919, 2001.
O’Dowd, C. D., Facchini, M. C., Cavalli, F., Ceburnis, D., Mircea, M., Decesari, S., Fuzzi, S., Yoon, Y. J., and Putaud, J.-P.: Biogenically driven organic contribution to marine aerosol, Nature, 431, 676-680, 2004.

Oliveira, C., Pio, C., Alves, C., Evtyugina, M., Santos, P., Gonçalves, V., Nunes, T., Silvestre, A. J. D., Palmgren, F., Wåhlin, P., and Harrad, S.: Seasonal distribution of polar organic compounds in the urban atmosphere of two large cities from the North and South of Europe, Atmos. Environ., 41, 5555-5570, doi:10.1016/j.atmosenv.2007.03.001, 2007.

Oros, D. R. and Simoneit, B. R. T.: Identification and emission factors of molecular tracers in organic aerosols from biomass burning Part 2. Deciduous trees, Applied Geochemistry, 16, 15451565, doi:10.1016/s0883-2927(01)00022-1, 2001.

Osthoff, H. D., Roberts, J. M., Ravishankara, A. R., Williams, E. J., Lerner, B. M., Sommariva, R., Bates, T. S., Coffman, D., Quinn, P. K., Dibb, J. E., Stark, H., Burkholder, J. B., Talukdar, R. K., Meagher, J., Fehsenfeld, F. C., and Brown, S. S.: High levels of nitryl chloride in the polluted subtropical marine boundary layer, Nature Geosci., 1, 324-328, 2008.

Pavuluri, C. M., Kawamura, K., and Swaminathan, T.: Watersoluble organic carbon, dicarboxylic acids, ketoacids, and \&\#945; -dicarbonyls in the tropical Indian aerosols, J. Geophys. Res., 115, D11302, doi:10.1029/2009jd012661, 2010.

Pechtl, S. and von Glasow, R.: Reactive chlorine in the marine boundary layer in the outflow of polluted continental air: A model study, Geophys. Res. Lett., 34, L11813, doi:10.1029/2007g1029761, 2007.

Perelygin, I. S. and Klimchuk, M. A.: Infrared spectra of coordinated acetone, J. Appl. Spectrosc., 20, 687-688, doi:10.1007/bf00607479, 1974.

Renbaum, L. H. and Smith, G. D.: Artifacts in measuring aerosol uptake kinetics: the roles of time, concentration and adsorption, Atmos. Chem. Phys., 11, 6881-6893, doi:10.5194/acp-11-68812011, 2011.

Rudich, Y.: Laboratory Perspectives on the Chemical Transformations of Organic Matter in Atmospheric Particles, Chem. Rev. 103, 5097-5124, doi:10.1021/cr020508f, 2003.

Schauer, J. J., Kleeman, M. J., Cass, G. R., and Simoneit, B. R. T.: Measurement of Emissions from Air Pollution Sources. 3. C1C29 Organic Compounds from Fireplace Combustion of Wood, Environ. Sci. Technol., 35, 1716-1728, doi:10.1021/es001331e, 2001.

Schauer, J. J., Kleeman, M. J., Cass, G. R., and Simoneit, B. R.: Measurement of emissions from air pollution sources. 4. C1-C27 organic compounds from cooking with seed oils, Environ. Sci. Technol., 36, 567-575, 2002.

Sciare, J., Oikonomou, K., Favez, O., Liakakou, E., Markaki, Z., Cachier, H., and Mihalopoulos, N.: Long-term measurements of carbonaceous aerosols in the Eastern Mediterranean: evidence of long-range transport of biomass burning, Atmos. Chem. Phys., 8, 5551-5563, doi:10.5194/acp-8-5551-2008, 2008.

Singleton, D. L., Paraskevopoulos, G., and Irwin, R. S.: Rates and mechanism of the reactions of hydroxyl radicals with acetic, deuterated acetic, and propionic acids in the gas phase, J. Am. Chem. Soc., 111, 5248-5251, doi:10.1021/ja00196a035, 1989.

Smith, I. W. M. and Ravishankara, A. R.: Role of HydrogenBonded Intermediates in the Bimolecular Reactions of the 
Hydroxyl Radical, J. Phys. Chem. A, 106, 4798-4807, doi:10.1021/jp014234w, 2002.

Smith, J. D., Kroll, J. H., Cappa, C. D., Che, D. L., Liu, C. L., Ahmed, M., Leone, S. R., Worsnop, D. R., and Wilson, K. R.: The heterogeneous reaction of hydroxyl radicals with submicron squalane particles: a model system for understanding the oxidative aging of ambient aerosols, Atmos. Chem. Phys., 9, 3209-3222, doi:10.5194/acp-9-3209-2009, 2009.

Spicer, C. W., Chapman, E. G., Finlayson-Pitts, B. J., Plastridge, R. A., Hubbe, J. M., Fast, J. D., and Berkowitz, C. M.: Unexpectedly high concentrations of molecular chlorine in coastal air, Nature, 394, 353-356, 1998.

Tervahattu, H., Hartonen, K., Kerminen, V.-M., Kupiainen, K., Aarnio, P., Koskentalo, T., Tuck, A. F., and Vaida, V.: New evidence of an organic layer on marine aerosols, J. Geophys. Res., 107, 4053, doi:10.1029/2000jd000282, 2002a.

Tervahattu, H., Juhanoja, J., and Kupiainen, K.: Identification of an organic coating on marine aerosol particles by TOF-SIMS, J. Geophys. Res., 107, 4319, doi:10.1029/2001jd001403, 2002 b.

Tervahattu, H., Juhanoja, J., Vaida, V., Tuck, A. F., Niemi, J. V., Kupiainen, K., Kulmala, M., and Vehkamäki, H.: Fatty acids on continental sulfate aerosol particles, J. Geophys. Res., 110, D06207, doi:10.1029/2004jd005400, 2005.

Wang, G., Kawamura, K., Lee, S., Ho, K., and Cao, J.: Molecular, Seasonal, and Spatial Distributions of Organic Aerosols from Fourteen Chinese Cities, Environ. Sci. Technol., 40, 4619-4625, doi:10.1021/es060291x, 2006.
Wang, X., Luo, L., Ouyang, G., Lin, L., Tam, N. F. Y., Lan, C., and Luan, T.: One-step extraction and derivatization liquidphase microextraction for the determination of chlorophenols by gas chromatography-mass spectrometry, Journal of Chromatography A, 1216, 6267-6273, doi:10.1016/j.chroma.2009.07.011, 2009.

Westervelt, D. M., Moore, R. H., Nenes, A., and Adams, P. J.: Effect of primary organic sea spray emissions on cloud condensation nuclei concentrations, Atmos. Chem. Phys., 12, 89-101, doi:10.5194/acp-12-89-2012, 2012.

Yoon, Y. J., Ceburnis, D., Cavalli, F., Jourdan, O., Putaud, J. P., Facchini, M. C., Decesari, S., Fuzzi, S., Sellegri, K., Jennings, S. G., and O'Dowd, C. D.: Seasonal characteristics of the physicochemical properties of North Atlantic marine atmospheric aerosols, J. Geophys. Res., 112, D04206, doi:10.1029/2005jd007044, 2007.

Yu, J., Flagan, R. C., and Seinfeld, J. H.: Identification of Products Containing - $\mathrm{COOH},-\mathrm{OH}$, and - $\mathrm{CO}$ in Atmospheric Oxidation of Hydrocarbons, Environ. Sci. Technol., 32, 2357-2370, doi:10.1021/es980129x, 1998.

Zuo, Y., Zhang, K., and Lin, Y.: Microwave-accelerated derivatization for the simultaneous gas chromatographic-mass spectrometric analysis of natural and synthetic estrogenic steroids, Journal of Chromatography A, 1148, 211-218, doi:10.1016/j.chroma.2007.03.037, 2007. 